\title{
Dissociable Effects on Birdsong of Androgen Signaling in Cortex-Like Brain Regions of Canaries
}

\author{
(-Beau A. Alward, ${ }^{1,2}$ - Jacques Balthazart, ${ }^{3}$ and $\mathbb{Q}^{-}$Gregory F. Ball ${ }^{1,2}$ \\ ${ }^{1}$ Department of Psychological and Brain Sciences, Johns Hopkins University, Baltimore, Maryland 21218, ${ }^{2}$ Department of Psychology, University of \\ Maryland, College Park, College Park, Maryland 20742, and ${ }^{3}$ GIGA Neuroscience, University of Liège, 4000 Liège, Belgium
}

The neural basis of how learned vocalizations change during development and in adulthood represents a major challenge facing cognitive neuroscience. This plasticity in the degree to which learned vocalizations can change in both humans and songbirds is linked to the actions of sex steroid hormones during ontogeny but also in adulthood in the context of seasonal changes in birdsong. We investigated the role of steroid hormone signaling in the brain on distinct features of birdsong using adult male canaries (Serinus canaria), which show extensive seasonal vocal plasticity as adults. Specifically, we bilaterally implanted the potent androgen receptor antagonist flutamide in two key brain regions that control birdsong. We show that androgen signaling in the motor cortical-like brain region, the robust nucleus of the arcopallium (RA), controls syllable and trill bandwidth stereotypy, while not significantly affecting higher order features of song such syllable-type usage (i.e., how many times each syllable type is used) or syllable sequences. In contrast, androgen signaling in the premotor cortical-like brain region, HVC (proper name), controls song variability by increasing the variability of syllable-type usage and syllable sequences, while having no effect on syllable or trill bandwidth stereotypy. Other aspects of song, such as the duration of trills and the number of syllables per song, were also differentially affected by androgen signaling in HVC versus RA. These results implicate androgens in regulating distinct features of complex motor output in a precise and nonredundant manner.

Key words: androgens; birdsong; neuroendocrinology; steroid hormones; vocal plasticity

\section{Significance Statement}

Vocal plasticity is linked to the actions of sex steroid hormones, but the precise mechanisms are unclear. We investigated this question in adult male canaries (Serinus canaria), which show extensive vocal plasticity throughout their life. We show that androgens in two cortex-like vocal control brain regions regulate distinct aspects of vocal plasticity. For example, in HVC (proper name), androgens regulate variability in syntax but not phonology, whereas androgens in the robust nucleus of the arcopallium (RA) regulate variability in phonology but not syntax. Temporal aspects of song were also differentially affected by androgen signaling in HVC versus RA. Thus, androgen signaling may reduce vocal plasticity by acting in a nonredundant and precise manner in the brain.

\section{Introduction}

Songbirds and humans share similarities in how they learn their vocalizations (Marler, 1970; Doupe and Kuhl, 1999; Tchernichovski et al., 2001; Brenowitz et al., 2010; Brainard and Doupe, 2013; Lipkind et al., 2013; Tchernichovski and Marcus, 2014). Both go through a series of developmental changes from stages

\footnotetext{
Received Oct. 31, 2016; revised July 14, 2017; accepted July 24, 2017.

Author contributions: B.A.A., J.B., and G.F.B. designed research; B.A.A. performed research; B.A.A. and G.F.B. analyzed data; B.A.A., J.B., and G.F.B. wrote the paper.

This work was supported by National Institutes of Health/National Institute of Neurological Disorders and Stroke Grant R0135467 (G.F.B.) and Grant SSTC PAI P7/17 from the Belgian Science Policy (J.B. and G.F.B.). We thank Trevor Chan, Hope Lundberg, and Shannon Parker for technical assistance.

The authors declare no competing financial interests.

Correspondence should be addressed to Beau A. Alward, Department of Biology, Stanford University, Stanford, CA 94305. E-mail: balward@stanford.edu.

DOI:10.1523/JNEUROSCI.3371-16.2017

Copyright $\odot 2017$ the authors $\quad 0270-6474 / 17 / 378612-13 \$ 15.00 / 0$
}

that are characterized by a high degree of vocal variability to a less variable stage in which vocal behavior is more stable (Marler, 1970; Doupe and Kuhl, 1999; Brainard and Doupe, 2013). Vocal learning in humans involves a process by which vocal variability during the babbling phase leads eventually to the production of clear words at $\sim 1$ year (Brainard and Doupe, 2013). Vocalizations continue to be dynamic and subject to change based on experience until puberty, after which some of the most dramatic changes in vocalizations (e.g., the ability to learn other languages) are attenuated (Johnson and Newport, 1989). This attenuation of vocal plasticity correlates with an increase in sex steroid hormones at puberty, and testosterone $(\mathrm{T})$ concentrations during early development (i.e., 1-3 months of age) negatively predict vocal plasticity at 18-30 months of age (Johnson and Newport, 1989; Kung et al., 2016).

A similar process occurs in songbirds who first go through a sensory stage when they are nestlings and form an auditory mem- 
ory of the tutor song (for review, see Hultsch and Todt, 2004). They then experience a sensorimotor phase that in temperate zone songbirds occurs during the following spring. The sensorimotor phase starts with a period of quiet variable vocalizations labeled subsong (akin to babbling) followed by periods of highly variable song with adult elements called plastic song that culminates in stable crystallized song. Experiments in sparrows demonstrated that this process of moving from variable song to stable crystallized song is dependent on T (Marler et al., 1988). Castrated male sparrows failed to transition out of the plastic song state, whereas treatment with $\mathrm{T}$ induced crystallization; in some birds the T implant was removed and the birds returned to a state of plastic song (Marler et al., 1988). Some seasonally breeding songbirds such as male canaries (Serinus canaria) additionally undergo substantial changes in vocal stability as adults: during the fall (i.e., nonbreeding season) when $\mathrm{T}$ concentrations are low, they repeat the sensorimotor phase, and can produce a new crystallized song during the spring (i.e., breeding season) when $\mathrm{T}$ concentrations are high (Nottebohm et al., 1986).

The neural basis of vocal behaviors transitioning from a variable to a stable state can be investigated experimentally in songbirds. First, birdsong is controlled by a network of telencephalic nuclei with distinct functions (Fig. 1). Throughout this telencephalic brain circuit there is a distinct pattern of androgen receptor (AR) expression (Balthazart et al., 1992; Bernard et al., 1999; Gahr, 2001). Recent research makes it clear that T has nonredundant effects on song production in both the brain and the periphery (for review, see Alward et al., 2017). We know for example that the motivation to sing can be activated by $\mathrm{T}$ acting outside the song system in the medial preoptic nucleus (POM; Alward et al., 2013). However, song stimulated by $\mathrm{T}$ action only in the POM lacks stereotypy and the simultaneous implantation in HVC rescues the deficit (Alward et al., 2016c). A gap in our knowledge concerns what the specific effects of $\mathrm{T}$ are in two key forebrain song control nuclei that express AR, HVC, and robust nucleus of the arcopallium (RA; Fig. 1); these nuclei are essential for controlling fundamental aspects of song such as syllable acoustic structure (RA; Yu and Margoliash, 1996; Sober et al., 2008), syllable sequencing, and which syllable types are used (HVC; Bouchard and Brainard, 2013; Basista et al., 2014).

Here, we investigate these questions in canaries, which maintain their ability to alter their song in adulthood (Nottebohm et al., 1986; Gahr et al., 2001), making them an excellent model system in which to study the androgenic regulation of vocal plasticity. We blocked AR selectively in HVC and RA to assess what aspects of song are supported by $\mathrm{T}$ acting in these nuclei specifically.

\section{Materials and Methods}

Animals used and pre-experimental manipulations. The protocols and procedures used here were approved by the Johns Hopkins University Animal Care and Use Committee (Protocol: AV14A112). Twenty-eight male canaries (Serinus canaria) of the Border strain were used for this study. Canaries were obtained from a local breeder (Maryland Exotic Birds). All birds were 1-2 years of age and had all experienced at least one breeding season before the beginning of the present study. Upon entry into the laboratory, birds were placed on a short-day photoperiod $(8 / 16 \mathrm{~h}$ light/dark) for 6 weeks to induce photosensitivity (Nicholls and Storey, 1977; Hurley et al., 2008). Birds were housed in mixed-sex groups.

Bilateral implantation of flutamide targeting HVC or RA. Birds were anesthetized using isoflurane gas (3-4\%) and implanted subcutaneously with T-filled SILASTIC implants (Dow Corning; outside diameter $=1.65 \mathrm{~mm}$, inside diameter $=0.76 \mathrm{~mm} ; 12 \mathrm{~mm}$ in length filled with $10 \mathrm{~mm}$ of T, Sigma-Aldrich T-1500; RRID: CHEBI:17347) in the same fashion as in our previous studies (Alward et al., 2013, 2016c). We im-

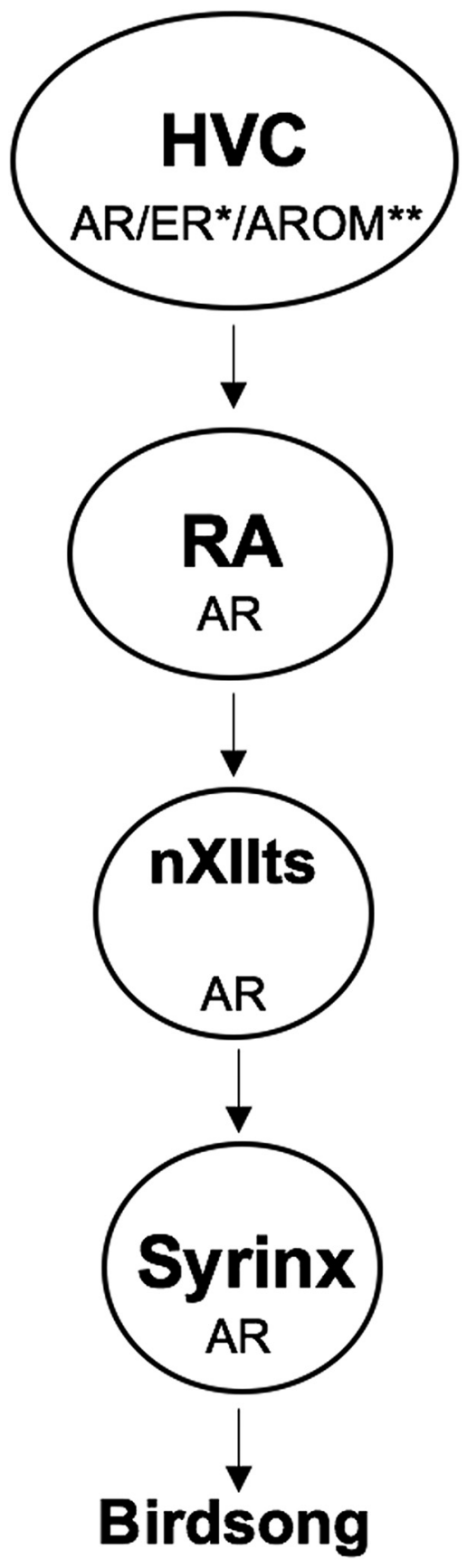

Figure 1. Steroid hormone receptors are expressed throughout the vocal motor pathway of the song control circuit. This simplified schematic shows the distribution of ARs, ERs, and aromatase (AROM), the enzyme that converts T to estradiol, in the vocal motor pathway (VMP) of the song control system. HVC (proper name) projects to RA. RA controls motor neurons in the tracheosyringeal portion of the twelfth cranial nerve (nXIlts), which in turn controls the muscles of the syrinx, the avian vocal organ, to generate birdsong. ARs are expressed at every level of the VMP, whereas ERs are expressed only in HVC. *ER is expressed in HVC only in some species, including canaries (Ball et al., 2002). **AROM mRNA is not found in HVC, but AROM protein has been observed in presynaptic boutons in HVC in zebra finches (Peterson et al., 2005).

planted all birds with subcutaneous $\mathrm{T}$ given observations in our laboratory and others that some males sing at very low rates (Calder, 1970; Alward et al., 2016b) and that laboratory held males have lower plasma $\mathrm{T}$ concentrations than wild-caught individuals even when held on long days (Calder, 1970; Meitzen et al., 2007). Implanting all birds with T thus increased experimental and statistical power. Others have used similar techniques in different songbird species to ensure high rates of singing (Meitzen et al., 2007). 
Immediately following subcutaneous implantation of $\mathrm{T}$, birds were placed in a stereotaxic apparatus modified for use in small birds such as canaries with the beak holder placed $45^{\circ}$ below the horizontal axis of the apparatus and then continued to be exposed to isoflurane gas. We used an identical implant procedure as in our previous work but performed bilateral instead of unilateral implants (Alward et al., 2013, 2016c). Birds were bilaterally implanted with 27-gauge cannulae targeting HVC or RA filled with crystalline flutamide (Sigma-Aldrich, Flutamide F9397; RRID: CHEBI:5132) or left empty as a control. Needles were filled over a length of $\sim 2 \mathrm{~mm}$ with flutamide using a technique identical to Balthazart and Surlemont (1990). Implants were cleaned using acetone and a Kimwipe to remove any flutamide that stuck to the outside of the cannula.

Flutamide is a potent nonsteroidal androgen receptor antagonist that has been used extensively in songbirds and other species as a global and a local antagonist for androgen signaling, with no reports of apparent toxicity or off-target effects (Balthazart and Surlemont, 1990; Bottjer and Hewer, 1992; Soma et al., 1999b; Singh et al., 2000; Naghdi et al., 2001; Brown, 2004; Van Duyse et al., 2005; Grisham et al., 2007; Meitzen et al., 2007; Fuxjager et al., 2012; Hejmej et al., 2013).

In line with previous work, our goal was to place each cannula near but not into HVC or RA (Meitzen et al., 2007; Alward et al., 2013, 2016c). Thus, implants were placed lateral to HVC and dorsolateral to RA. Of course, for HVC it would have been optimal to place the cannulae directly dorsal to (i.e., above) the nucleus; however, this is particularly challenging given that in all likelihood the cannulae would not remain in place and/or deliver flutamide into the adjacent lateral ventricle. Moreover, it is paramount to avoid inserting the cannulae directly into the nucleus, given the possibility of damage to the nucleus of interest. Indeed, lesions in different parts of HVC lead to changes in neural activity in a highly topographical manner (Stauffer et al., 2012) and medial versus lateral portions of HVC regulate distinct features of song (Basista et al., 2014). This technique has been used previously in neuroendocrine studies and shown to be effective in delivering the compound of interest while avoiding damage to the nucleus of interest, which could lead to confounding effects (Meitzen et al., 2007; Alward et al., 2013, 2016c).

Coordinates for targeting HVC were as follows: $-0.6 \mathrm{~mm}$ from the dorsal surface of the brain, anterior-posterior: $-2.3 \mathrm{~mm}$ from the rostral tip of the cerebellum, and medial-lateral: $\pm 3.0 \mathrm{~mm}$ from midline. Coordinates for RA were as follows: $-2.40 \mathrm{~mm}$ from the dorsal surface of the brain, anterior-posterior: $-0.9 \mathrm{~mm}$ from the rostral tip of the cerebellum, and medial-lateral: $\pm 2.70 \mathrm{~mm}$ from midline. Fifteen canaries were implanted with cannulae bilaterally targeting HVC: 12 of these birds were implanted with flutamide (HVC-flut) and three birds were implanted with empty cannulae (HVC-noflut). Thirteen canaries were implanted bilaterally with cannulae targeting RA: 10 of these birds were implanted with flutamide (RA-flut) and three birds were implanted with empty cannulae (RA-noflut). The relatively lower numbers for the "empty" controls were chosen based on expected variation in implant sites and the fact that AR blockade in HVC and RA affects singing behavior in a specific manner only when the implants are near the edge of the nucleus (Meitzen et al., 2007). Moreover, the implant procedure we used here has been shown to produce highly localized effects on the brain nucleus of interest (Alward et al., 2013, 2016c). This is largely explained by the fact that in all songbirds in which AR expression patterns have been studied, including canaries, ARs are expressed in HVC and RA but not in the surrounding nidopallium and arcopallium (Balthazart et al., 1992; Smith et al., 1996; Gahr and Metzdorf, 1997; Bernard et al., 1999; Soma et al., 1999a). Data from birds with flutamide cannulae that were found to be located too distant from HVC or RA (see below) were pooled with data from the corresponding control group after confirming by statistical analyses that they did not differ.

Animal housing and care. Immediately following stereotaxic implantation, birds were placed individually in sound-attenuating recording chambers $(41 \times 48 \times 51 \mathrm{~cm})$ set to a long-day photoperiod $(14 / 10 \mathrm{~h}$ light/dark) to simulate breeding conditions (Nicholls and Storey, 1977; Hurley et al., 2008; Alward et al., 2014). Chambers contained a wooden perch and birds could move freely, perform wing stretching, dusting, and self-preening behavior. Each chamber was outfitted with a recording device that captured video and audio recordings (recording parameters are described below). All of these cameras were connected to a computer that allowed continuous real-time audiovisual observations of the individual birds. Birds were housed alone given our previous work demonstrating that male canaries sing when housed alone on long days but reduce singing substantially and sometimes do not sing at all when housed with a female (Alward et al., 2014).

Song recording and analysis. Isolation chambers were outfitted with a microphone (BT-MP8087 Mini microphone, B\&H Photo and Electronics) and camera (KPC-600 Pinhole Camera $3.6 \mathrm{~mm}$, B\&H Photo and Electronics) connected to a computer running DVRserver (v6.33b, Mammoth Technologies) designed for real-time video and audio surveillance recording. Each day, the DVRserver captured song behavior from 08:00 to 10:30 A.M. (lights on at 08:00 A.M.) in .wav files sampled at $22,050 \mathrm{~Hz}$ which translated to a frequency range of $0-11 \mathrm{kHz}$. Song files were run through a high-pass filter set to a threshold of $900 \mathrm{~Hz}$ to remove low-frequency noise and converted to a digital format using Goldwave (v5.55) before they were visualized into sound spectrograms using Avisoft (SASlab Pro, RRID: SCR_014438), a Windows application for investigating animal acoustic communication. For the spectrograms, the fast Fourier transform length was set to 512 with an overlap of $75 \%$ for the temporal resolution. Songs were defined as vocalizations having a duration $>1$ s with no gaps longer than 500 milliseconds (Voigt and Leitner, 2008; Alward et al., 2013, 2014, 2016a,b,c). Spectrograms were visually inspected to further eliminate noise that escaped the filter.

Based on work by Meitzen et al. (2007) and Alward et al. (2013), we intended to analyze song during an early (e.g., day 10), middle (e.g., day 14), and later time point (e.g., day 21, the last day of treatment). However, we found that on some of the early and middle days some birds did not sing during our recording time from 08:00 to 10:30 A.M. These observations are very similar to what we observed in a recent study from our laboratory (Alward et al., 2016b) and the time course for the increase in song rate for all birds regardless of hormone treatment was also very similar to what we observed our previous work (Alward et al., 2016b). Therefore, we analyzed songs during time blocks over days 10-12 and days 13-14, which allowed us to include all birds in our analyses and to perform repeated-measures ANOVAs which increased our statistical power. Meitzen et al. (2007) used nearly identical sampling periods in their study on singing in white-crowned sparrows when males were implanted with AR or estrogen receptor (ER) antagonists targeting HVC. Other studies have also binned across days when analyzing changes in song (Pytte et al., 2012; Madison et al., 2015).

Quantification of song rate and whole-song bandwidth stereotypy. Song rate (no. of songs/hour) was determined by dividing the total number of songs sung by each bird during each time bin by the total number of hours analyzed within that time bin. We also quantified whole-song bandwidth stereotypy. We have shown previously that the stereotypy of whole-song bandwidth (bandwidth = the difference between the minimum and maximum frequency) changes substantially as a function of $\mathrm{T}$ action in canaries (Alward et al., 2013, 2016c). Using the Avisoft software package, we quantified the bandwidth of each whole song on each analysis day. We then computed whole-song bandwidth coefficient of variation $(\mathrm{CV})$, which is the $\mathrm{SD}$ of bandwidth across individual songs produced by a given bird, divided by the average bandwidth across those songs multiplied by 100 . CV is a measure of consistency of an acoustic feature over renditions of songs and has been used extensively in birdsong studies as a measure of song stereotypy (Meitzen et al., 2007; Sakata et al., 2008; Alward et al., 2013, 2016a,b,c). A higher value of whole-song bandwidth CV means that over song renditions, the bandwidth of whole song is less stereotypic.

Quantification of trill and syllable bandwidth stereotypy. We were also interested in quantifying the bandwidth stereotypy of units of song that vary over distinct temporal domains. Syllables are considered to be in the shortest temporal domain, and are the minimal units of production of birdsong that, when strung together, form phrases. Phrases are then strung together to form whole songs (Catchpole and Slater, 2003). Previous work suggests that these distinct temporal domains are controlled differentially by HVC and RA (Margoliash, 1997).

A particular type of canary phrase is referred to as a trill, which is the fast repetition of a syllable type (Catchpole and Slater, 2003). We ana- 

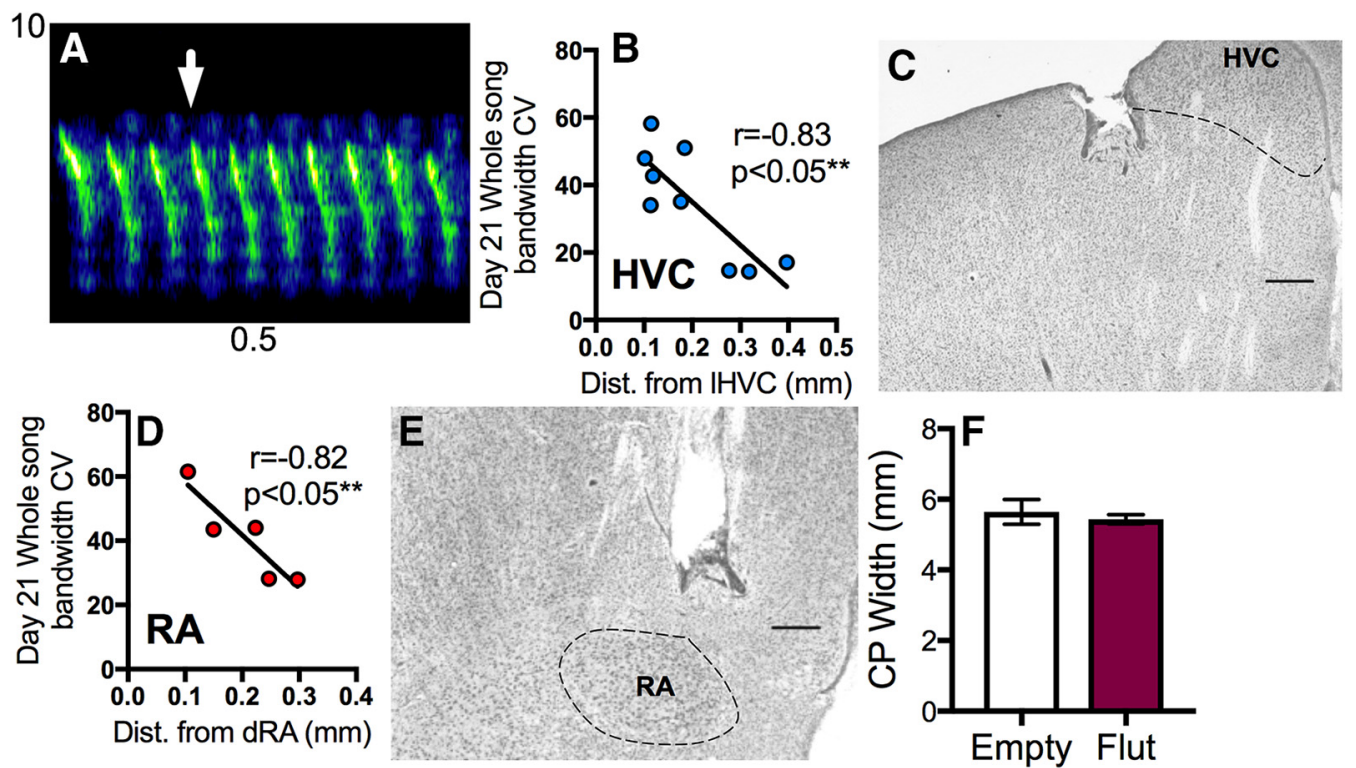

Figure 2. Flutamide specificity and syllable of interest for analysis of bandwidth stereotypy. $A$, The white arrow indicates an example of the syllable used in the automated syllable analysis. $B$, Effects of flutamide-filled implants targeting the area directly adjacent to HVC were correlated to their distance medial to the lateral part of HVC (IHVC). All birds with flutamide-filled implants presented here were in the "Flut" group as their cannula tip was in each case near HVC. C, Photomicrograph of Nissl-stained section illustrating an implant located near HVC (delineated by dashed border). D. Flutamide-filled implants targeting RA were also highly spatially effective depending on their distance dorsal to the dorsal edge of RA (dRA). $\boldsymbol{E}$, Photomicrograph of Nissl-stained section illustrating an implant located near RA (delineated by dashed border). $\boldsymbol{F}$, (P was not different in birds treated with empty cannula (Ctrl) or flutamide-filled cannula (Flut), suggesting flutamide did not leak into the general circulation (Tramontin et al., 2003; Alward et al., 2016c). Scale bars: C, E, $200 \mu \mathrm{m}$.

lyzed the bandwidth stereotypy of trills, given previous work showing seasonal changes in trill production in wild canaries (Voigt and Leitner, 2008). Trills were quantified similarly as in Alward et al. (2016b). Briefly, we visually inspected songs for trills sung within a bout of continuous singing of $5 \mathrm{~min}$. Using this visual inspection method, we were able to identify particular trill types. To quantify the bandwidth of each trill, we dragged the cursor over each trill, manually labeled each trill, and then computed bandwidth. Bandwidth stereotypy was analyzed for each trill separately and then collapsed into an overall trill stereotypy value. We and others analyzing canary song have also used a visual inspection method for the quantification of individual song components such as trills and syllables (Markowitz et al., 2013; Alward et al., 2016b).

Previous studies assessing different components of canary song have analyzed syllable acoustic stereotypy based on the features of a common syllable type; i.e., a syllable type sung by most or all birds (Iserbyt et al., 2017). While quantifying trills across birds, it became apparent that each bird sang a common syllable type that possessed distinct acoustic and temporal features that permitted an automatic analysis of this particular syllable type for all subjects (Fig. $2 A$ ).

Therefore, we quantified in all birds this particular syllable type to determine syllable bandwidth stereotypy. These syllables were sung in succession as part of a trill. To conduct an unbiased analysis of the stereotypy of these syllables, 40 of these syllables were randomly selected for each bird and each day from the total number of syllables detected and they were quantified based on the same features we used for trills and overall songs. An alternative approach would be to attempt to analyze the acoustic features of all syllables across the songs of the birds included in this study. However, the strategy we used in this study is valid and produced meaningful and interpretable results. Indeed, our goal was to assess how androgen signaling in HVC versus RA may regulate distinct features of canary song and previous investigators have successfully used approaches similar to ours to investigate different features of canary songs, trills, and syllables (Nottebohm et al., 1986; Leitner et al., 2001; Alward et al., 2013, Alward et al., 2016a,b,c; Markowitz et al., 2013; Iserbyt et al., 2017.

Quantification of the variability of syllable-type usage and syllable sequencing. Canaries sing a variety of syllable types (Nottebohm et al., 1986; Catchpole and Slater, 2003). Syllable types were labeled manually in Avisoft by placing brackets around the whole rendition of that syllable type. Within a given year, canaries do not change the number of different syllables they produce, but the variability of how often each syllable type is used (hereon called "syllable-type usage variability") and how they are sequentially arranged has been shown to change seasonally (Nottebohm et al., 1986). For each bird on the days on which song was analyzed, we manually labeled syllables in 10-20 songs or $\sim 180-300$ syllables. Different syllables can be labeled reliably by visual means, and manual labeling methods have been used by us and others when quantifying different syllable types in canary song (Nottebohm et al., 1986; Leitner et al., 2001; Markowitz et al., 2013; Alward et al., 2016b; Iserbyt et al., 2017).

To assess syllable-type usage variability, we quantified the zero-order entropy of syllable usage, which is defined as follows:

$$
\text { zero-order entropy }=-\Sigma p_{\mathrm{i}} \times \log _{2}\left(p_{\mathrm{i}}\right)
$$

where the sum is over all of the different syllables and $p_{\mathrm{i}}$ is the probability of each syllable occurrence. Zero-order entropy values were standardized across birds to the maximum amount of entropy possible by the following formula:

syllable-type usage variability $=$ zero-order entropy $/ \log _{2}(y)$,

where $y$ is the number of different syllable types produced by each bird, as done in previous work (Parker, 2009). This yielded syllable-type usage variability values between 0 and 1 , where 1 is the maximum possible entropy (i.e., maximum randomness or variability of syllable-type usage). The higher this number, the more variable is syllable-type usage.

We measured syllable sequence variability by methods similar to others (Nottebohm et al., 1986; Sakata et al., 2008; Matheson et al., 2016). We analyzed for each bird transitions from its dominant (i.e., most frequently used) syllable type to all other types. We first determined the dominant syllable type from the labeled syllables that were used for quantifications of syllable-type usage variability and then quantified first order entropy for the dominant syllable type by:

$$
\text { first-order entropy }=-\Sigma p_{\mathrm{i}} \times \log _{2}\left(p_{\mathrm{i}}\right)
$$

where the sum is over all over possible transitions and $p_{\mathrm{i}}$ is the probability of the $i$ th transition from the dominant syllable type. As for syllable-type 
usage variability, we standardized this measure with the following formula:

syllable sequence variability $=$ first-order entropy $/ \log _{2}(z)$.

where $z$ is the number of different syllables that followed the dominant syllable type. This yielded syllable sequence variability values between 0 and 1 , where 1 is the maximum possible entropy (i.e., maximum randomness or variability of syllable sequence). In some cases, the dominant syllable type was the first syllable in a part of a syllable sequence that occurred $>95 \%$ of the time. These types of transitions are considered to be fully stereotyped sequences (e.g., similar to motifs in zebra finch songs). For these situations, we treated the transitions from these stereotyped sequences as "branch points" (e.g., in the fully stereotyped sequence $\mathrm{A}-\mathrm{B}$, the transitions from $\mathrm{B}$ were used for calculating first order entropy) as done in previous studies (Sakata et al., 2008; Hampton et al., 2009; Tchernichovski and Marcus, 2014; Matheson et al., 2016). There was no effect of treatment on the presence of dominant syllable types that were defined as branch points.

Brain extraction, fixation, and cloacal protuberance measurements. Twenty-one days after treatment initiation, birds were deeply anesthetized (4\% isoflurane), weighed, rapidly decapitated, and their brain was extracted and fixed in acrolein. Brains were agitated in 5\% acrolein for $2 \mathrm{~h}$, and then washed for $15 \mathrm{~min}$ four times in PBS and cryoprotected in $30 \%$ sucrose overnight. Brains were flash frozen in dry ice for $5 \mathrm{~min}$ and then placed into $\mathrm{a}-70^{\circ} \mathrm{C}$ freezer. We also measured the length and width of the cloacal protuberance (CP), an androgen-sensitive organ (Meitzen et al., 2007; Alward et al., 2016a). If flutamide did not enter into the general circulation, all birds should experience a similar increase in the size of the CP after being exposed to long days and a SILASTIC T implant.

Cryosectioning and histological verification of implant site. Brains were sectioned on a cryostat from the olfactory bulb to the brainstem in four series of 30- $\mu \mathrm{m}$-thick transverse sections that were stored in cryoprotectant into a $-20^{\circ} \mathrm{C}$ freezer. One series was later mounted on gelatincoated slides and exposed to air for a day. These mounted sections were then Nissl stained and coverslipped using Permount (Fisher Scientific).

Photomicrographs of HVC and RA were taken at $2.5 \times$ magnification in the Nissl-stained sections using an Axiocam attached to a Zeiss Axioskop. HVC and RA are easily identifiable in Nissl-stained sections and the cannula tracts were also readily apparent as in our previous studies (Alward et al., 2013, 2016c). We determined the implant locations under microscopic analysis and took images of the implant tracts. Using ImageJ (NIH; RRID: SCR_003070) we quantified the distance from the cannula tip to either HVC or RA in the rostrocaudal, dorsoventral, or mediolateral plane for all birds that received bilateral flutamide implants.

Specificity of action for flutamide-filled cannulae was determined by correlating the functional response (whole-song bandwidth stereotypy) with the position of the cannulae relative to the brain region-of-interest. As mentioned above, for HVC, the goal was to place the cannula tips adjacent (lateral) to the nucleus to minimize damage to the nucleus (Meitzen et al., 2007). For RA, the goal was to place cannula tips directly above or adjacent to the nucleus for the same reason (Meitzen et al., 2007; Larson et al., 2013). For HVC, only distance of the cannula tip lateral to HVC was used to determine specificity because most cannula tips did not occur ventral to HVC, making a meaningful analysis of variation based on dorsoventral distance to HVC and whole-song stereotypy impossible. For RA, only variation in the dorsoventral plane was used as a reliable indicator of cannula distance, given that only one bird had a cannula tip that did not occur directly dorsal to RA (i.e., values for distance in the medial-lateral plane for cannula tips were mostly "zero").

Distances were determined for each hemisphere separately. There were no differences between the left and right hemispheres in cannula distances from the nucleus of interest for HVC (unpaired $t$ test, $p=0.28$ ) or RA (unpaired $t$ test, $p=0.11$ ). Therefore, for each bird we averaged over both hemispheres the implant distances from each nucleus. Because all flutamide cannula that missed were substantially caudal to the caudal portion of the nucleus of interest, they were not included in a correlational analysis relating distance to HVC or RA and the effect on wholesong bandwidth stereotypy.
Statistical analyses. Mixed-design ANOVAs were used to determine the effects of AR antagonism in either region on song measures, using day (days 10-12, 13-14, and day 21) as the within-subjects factor and treatment (flutamide vs empty) as the between-subjects factor. GreenhouseGeisser-corrected $p$ values were used. Following significant interactions in the omnibus ANOVA, post hoc Scheffe's tests were used to determine the differences driving the interaction effects. A mixed-design ANOVA was also used to assess the effects of treatment on CP size, wherein time (pretreatment vs post-treatment) was the within-subjects factor and treatment (flutamide vs empty) was the between-subjects factor. Correlational analyses were conducted using Pearson's $r$. Effects were considered significant at $p \leq 0.05$. Effect sizes were calculated as partial eta squared $\left(\eta_{\mathrm{p}}^{2}\right)$ to describe the importance of a significant effect in the omnibus ANOVA.

\section{Results}

\section{Specificity of flutamide treatment}

Some birds had a lesioned HVC (3 birds) or lesioned RA ( 1 bird) or only had a unilateral implant located near HVC ( 1 bird) or RA ( 2 birds) instead of bilateral implants. Due to the sparse nature of this variation, these birds could not be placed into a specific treatment group and were thus excluded from statistical analysis.

Two birds treated with a flutamide implant targeting HVC that missed the nucleus (implant tip $>600 \mu \mathrm{m}$ caudal to the nucleus) were shown to have song stereotypy values that were not different from controls (unpaired $t$ test, $p=0.66$ ); they were thus added to the control group. A similar observation was made for two birds treated with flutamide targeting but missing RA (implant tip was $>400 \mu \mathrm{ms}$ dorsal to the nucleus; unpaired $t$ test, $p=$ 0.37 ); they were similarly added to the control group. Therefore, the final sample sizes were as follows: HVC: control, $n=5$; flutamide, $n=9$; RA: control, $n=5$; flutamide, $n=5$ (total $N=24)$.

The distance from the flutamide-filled cannula tip to the nucleus of interest was negatively correlated with the overall song stereotypy of the birds (Fig. $2 B-E$; for HVC: distance lateral to HVC vs day 21 song bandwidth CV, $n=9, r=-0.83, p<0.05$; for RA: distance dorsal to RA vs day 21 song bandwidth $\mathrm{CV}, n=5$, $r=-0.82, p<0.05)$.

The CP size did not differ between birds treated with flutamide or empty cannula (Fig. $2 F ; t_{(22)}=0.69, p=0.49$ ), indicating that flutamide did not leak into the general circulation (Bottjer and Hewer, 1992; Meitzen et al., 2007; Alward et al., 2016c).

\section{Androgen signaling in $\mathrm{HVC}$ and RA regulates whole-song bandwidth stereotypy but not the motivation to sing}

Song rate was not significantly affected by antagonism of ARs in either HVC ( $p>0.20$ for all sources of variation in the mixeddesign ANOVA; overall mean \pm SEM for HVC-Ctrl $=28.24 \pm$ 5.76 and HVC-flut $=32.68 \pm 7.41)$ or RA $(p>0.21$ for all sources of variation in the mixed-design ANOVA; overall mean \pm SEM for RA-Ctrl $=47.75 \pm 13.32$ and RA-flut $=$ $27.75 \pm 10.79)$, which is consistent with previous observations (Brenowitz and Lent, 2002; Meitzen et al., 2007; Alward et al., 2016c). The higher mean value in the RA-Ctrl group appears to be most likely due to one active singer (without this bird in the calculation the mean value for RA-Ctrl birds drops to 37.34).

Bilateral blockade of androgen signaling with flutamide in HVC caused whole songs to become less stereotyped as assessed by the whole-song bandwidth $\mathrm{CV}$ (Fig. $3 A, B$ : representative sonograms; $C-E$ : quantitative analysis; treatment, $p=0.17$; time, $p=0.03, \eta_{\mathrm{p}}^{2}=0.25$; time $\times$ treatment, $\left.p=0.001, \eta_{\mathrm{p}}^{2}=0.44\right)$. The significant interaction resulted from a difference between flutamide-treated and control birds on day 21 of treatment (Scheffe's 

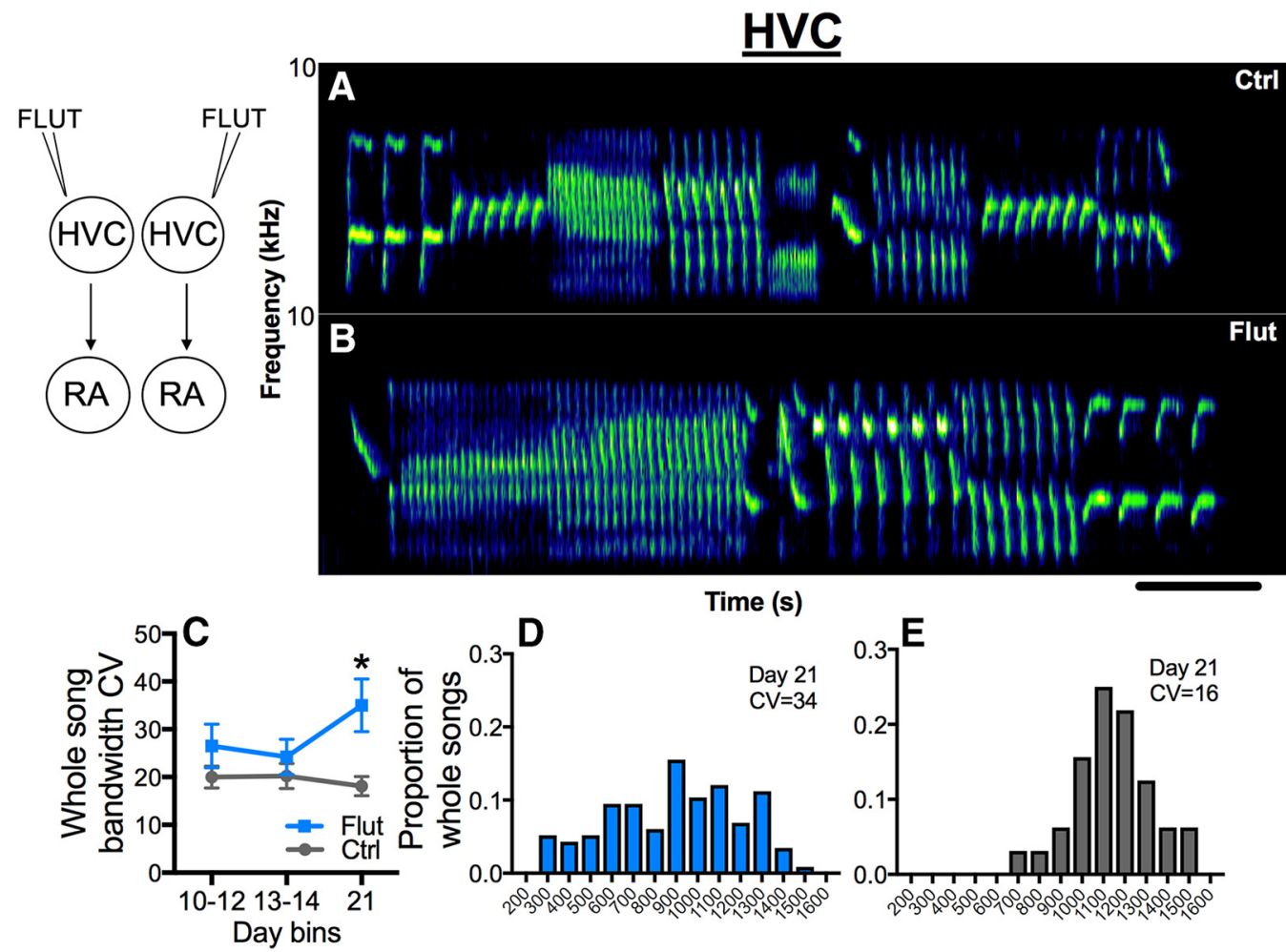

Figure 3. Androgen receptor antagonism in HVC bilaterally decreases whole-song bandwidth stereotypy. $\boldsymbol{A}, \boldsymbol{B}$, Examples of canary whole songs on day 21 from birds treated bilaterally with control (Ctrl) or flutamide-filled (Flut) cannula targeting HVC. Scale bar, 1 s. C, By day 21, AR blockade in HVC led to an increase in whole-song bandwidth CV, a measure of song stereotypy (the higher the $\mathrm{CV}$, the lower the stereotypy). Symbols represent mean \pm SEM. ${ }^{*} p<0.05$ compared with Ctrl on day $21 . \boldsymbol{D}, \boldsymbol{E}$, Histograms show the highly variable distribution of the proportion of whole songs sung at different bandwidths for birds with AR blocked in HVC (blue) or controls (gray) on day 21.

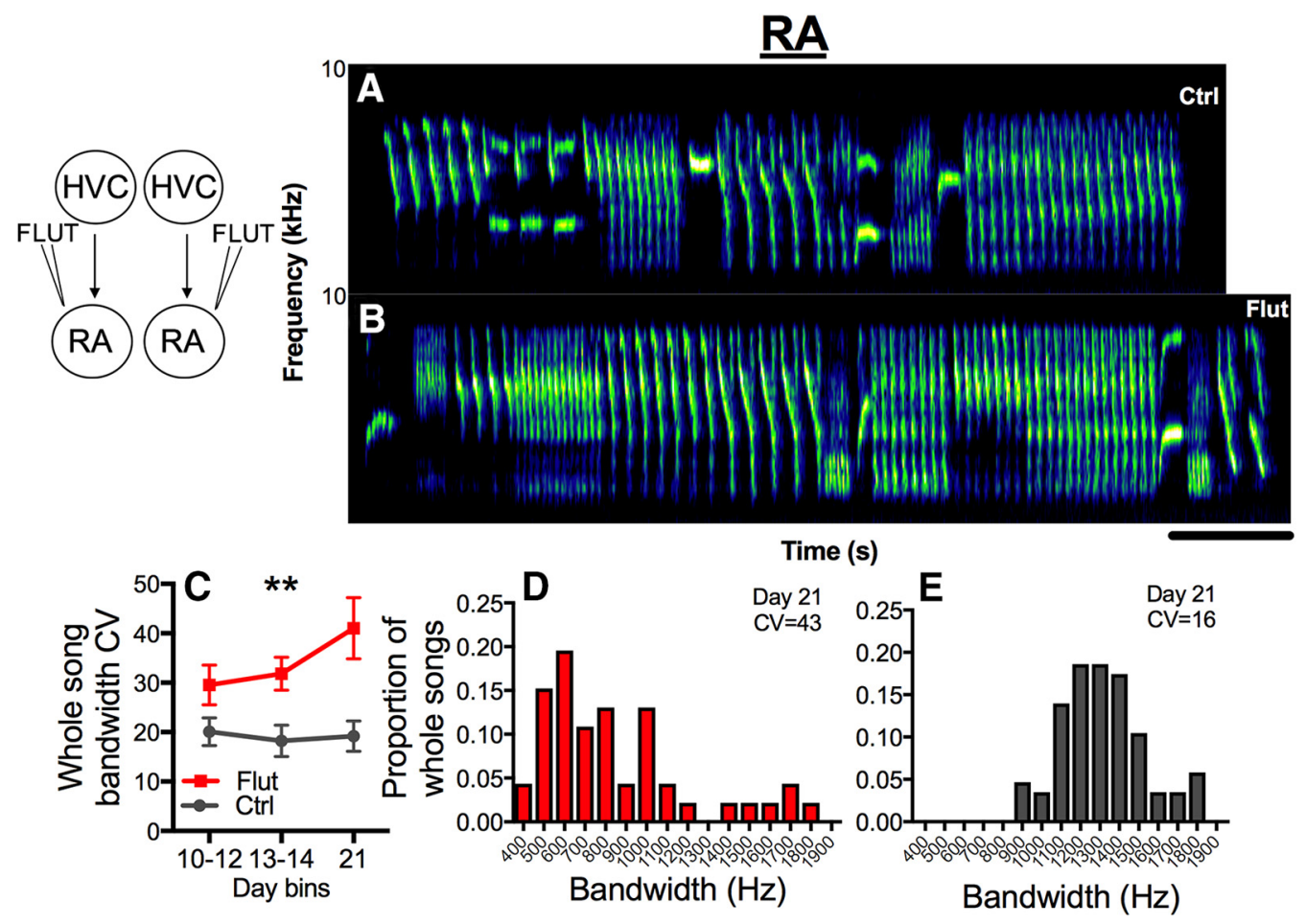

Figure 4. Androgen receptor antagonism in RA bilaterally decreases whole-song bandwidth stereotypy. $A, B$, Examples of canary whole songs on day 21 from birds treated bilaterally with control (Ctrl) or flutamide-filled (Flut) cannula targeting RA. Scale bar, 1 s. C, Androgen receptor blockade in RA led to a rapid, large increase whole-song bandwidth CV, a measure of song stereotypy (the higher the CV, the lower the stereotypy). Symbols represent mean \pm SEM. ${ }^{* *}$ At the top of a graph indicates $p=0.01$ for the overall effect of treatment. $D, E$, Histograms show the highly variable distribution of the proportion of whole songs sung at different bandwidths for birds with androgen receptors blocked in RA (red) or controls (dark gray) on day 21. 
post hoc tests, $p<0.05)$. Birds treated with flutamide bilaterally in RA also sang whole songs with lower whole-song bandwidth stereotypy than controls (Fig. 4A, B: representative sonograms; $C-E$ : quantitative analysis; time, $p=0.14$; treatment, $p=0.01, \eta_{\mathrm{p}}^{2}=0.56$; time $\times$ treatment, $p=0.12$ ).

\section{Androgen signaling in HVC versus RA controls distinct features of song bandwidth stereotypy}

Whole canary songs are composed of syllables, which are strung together to form phrases and trills. Canary song plasticity could thus be modulated in terms of not only the bandwidth stereotypy of whole songs, but also the stereotypy of individual song components such as syllable or trill bandwidth stereotypy, syllable sequencing, and/or overall syllable-type usage variability (i.e., the probability of specific syllable types being produced). Changes in one or more of these different components of song could give rise to an overall change in whole-song bandwidth stereotypy. For instance, the decrease in whole-song bandwidth stereotypy observed by day 21 in HVC-flut birds could be driven not only by changes in bandwidth stereotypy of individual syllables, but also by their arrangement (i.e., ordering or syntax). Some of these features have been shown to change seasonally (Voigt and Leitner, 2008), suggesting a modulation by gonadal steroids.

Blockade of androgen signaling in HVC had no effect on trill or syllable bandwidth stereotypy (Fig. $5 A, B$; trills: time, $p=0.91$; treatment, $p=0.42$; time $\times$ treatment, $p=$ 0.10 ; syllables: time, $p=0.32$; treatment, $p=0.88$; time $\times$ treatment, $p=0.34$ ). In contrast, antagonism of AR in RA caused birds to sing trills (Fig. $5 C$; time, $p=0.14$; treatment, $p=0.002, \eta_{\mathrm{p}}^{2}=0.71$; time $\times$ treatment, $p=0.91$ ) and syllables (Fig. $5 D$; time, $p=0.23$; treatment, $p=0.01, \eta_{\mathrm{p}}^{2}=$ 0.56 ; time $\times$ treatment, $p=0.18$ ) with reduced bandwidth stereotypy. Representative sonograms are shown in Figure 5E-J. Syllable, trill, and whole-song bandwidth stereotypy all correlated strongly with one another in males treated with flutamide in RA and their controls (Fig. $5 K-M$ ).

Antagonism of androgen signaling in HVC resulted in a substantial increase in syllable sequence variability (Fig. $6 A$; time, $p=0.74$; treatment, $p=0.009, \eta_{\mathrm{p}}^{2}=0.44$; time $\times$ treatment, $p=$ $0.81 ; B, C$ illustrate examples of syllable transitions in control vs flutamide subjects). Changes in syllable-type usage variability was similarly affected (increased syllable-type usage variability in flutamide birds; Fig. $6 D$; time, $p=0.29$; treatment, $p=0.43$; time $\times$ treatment, $p=0.04, \eta_{\mathrm{p}}^{2}=0.25$ ) but this effect developed more slowly and only became significant on day 21 (Scheffe's con- $\underline{\text { HVC }}$

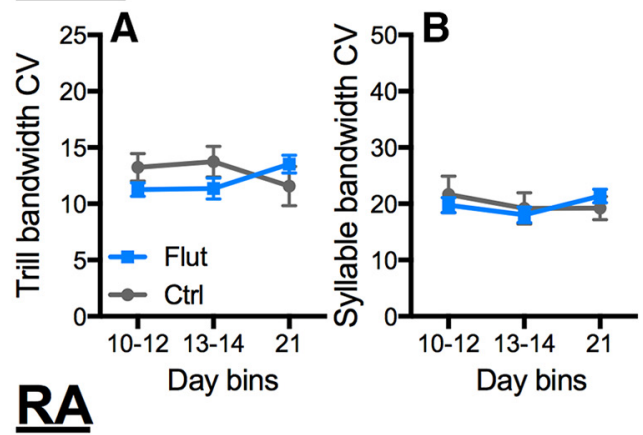

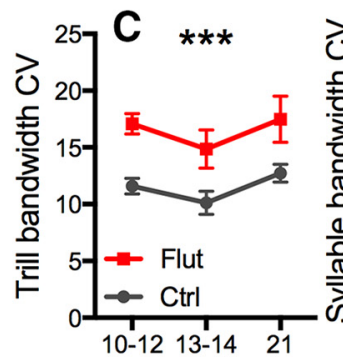

Day bins

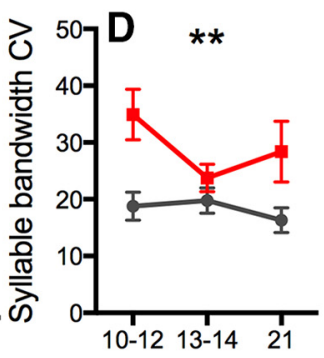

Day bins
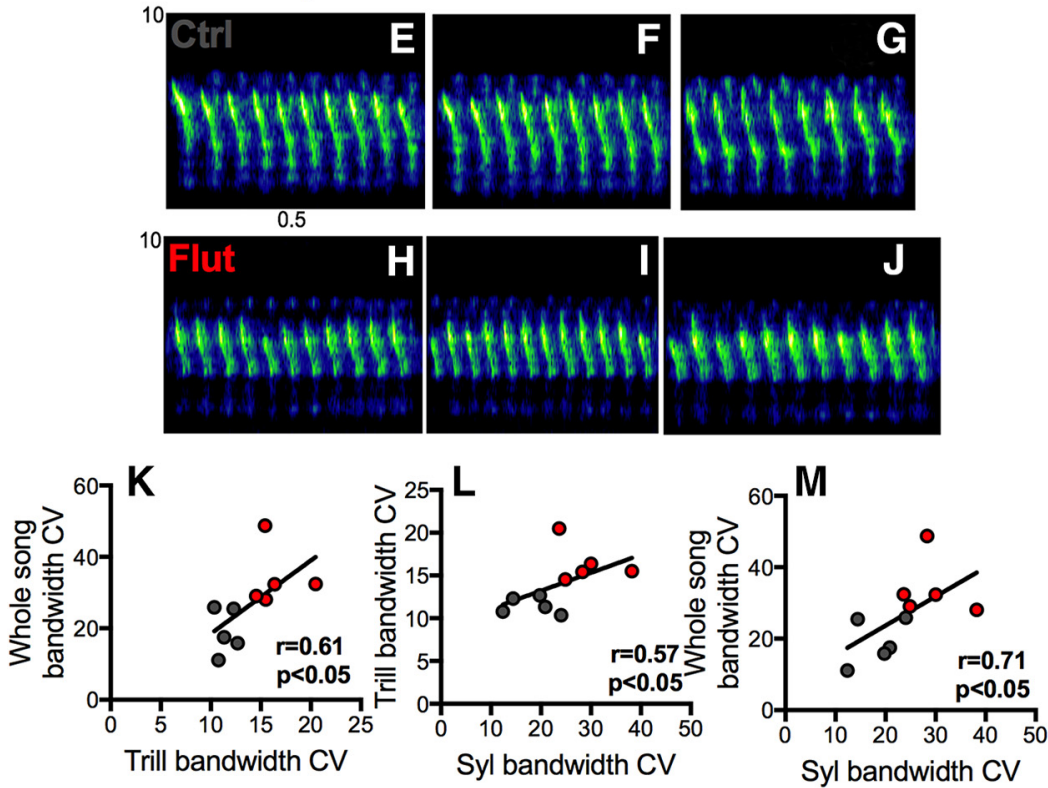

Figure 5. Androgen signaling in RA but not in HVC controls bandwidth stereotypy of syllables and trills. There were no differences between birds treated with flutamide-filled cannula in HVC (Flut) and controls (Ctrl) in terms of trill ( $\boldsymbol{A}$ ) and syllable ( $\boldsymbol{B}$ ) bandwidth CV, a measure of stereotypy (higher CV, lower stereotypy). $C, D, A R$ blockade in RA led to an increase in trill and syllable bandwidth CV. Symbols represent mean \pm SEM. ${ }^{* * *}$ At the top of a graph indicates $p<0.01$ for the overall effect of treatment; ${ }^{* *} p=0.01$ for an overall effect of treatment. $\boldsymbol{E}-\mathbf{G}$, Three successive trills sung by a control bird showing high stereotypy (i.e., low variability) from trill to trill as well as from syllable to syllable, compared with trills in birds with AR blocked in RA $(\boldsymbol{H}-\boldsymbol{J})$, which show lower stereotypy (i.e., more variability) from trill to trill and syllable to syllable. $\boldsymbol{K}-\boldsymbol{M}$, All measures of stereotypy correlated significantly with one another in birds treated with flutamide near RA and their controls. Symbols for individual birds are color-coded as in C, $\mathbf{D}$. trasts, $p<0.05)$. Figure $6, E$ and $F$, presents distribution charts showing the more variable use of different syllable types in flutamide birds compared with controls. Syllable-type usage variability correlated positively with whole-song bandwidth stereotypy, as measured by the whole-song bandwidth $\mathrm{CV}$, on day 21 (Fig. 6G-I), which could explain the decrease in whole-song bandwidth stereotypy on this day. On the other hand, there was no effect of AR antagonism in RA on syllable sequence variability (Fig. 6J; time, $p=0.76$; treatment, $p=0.81$; time $\times$ treatment, 

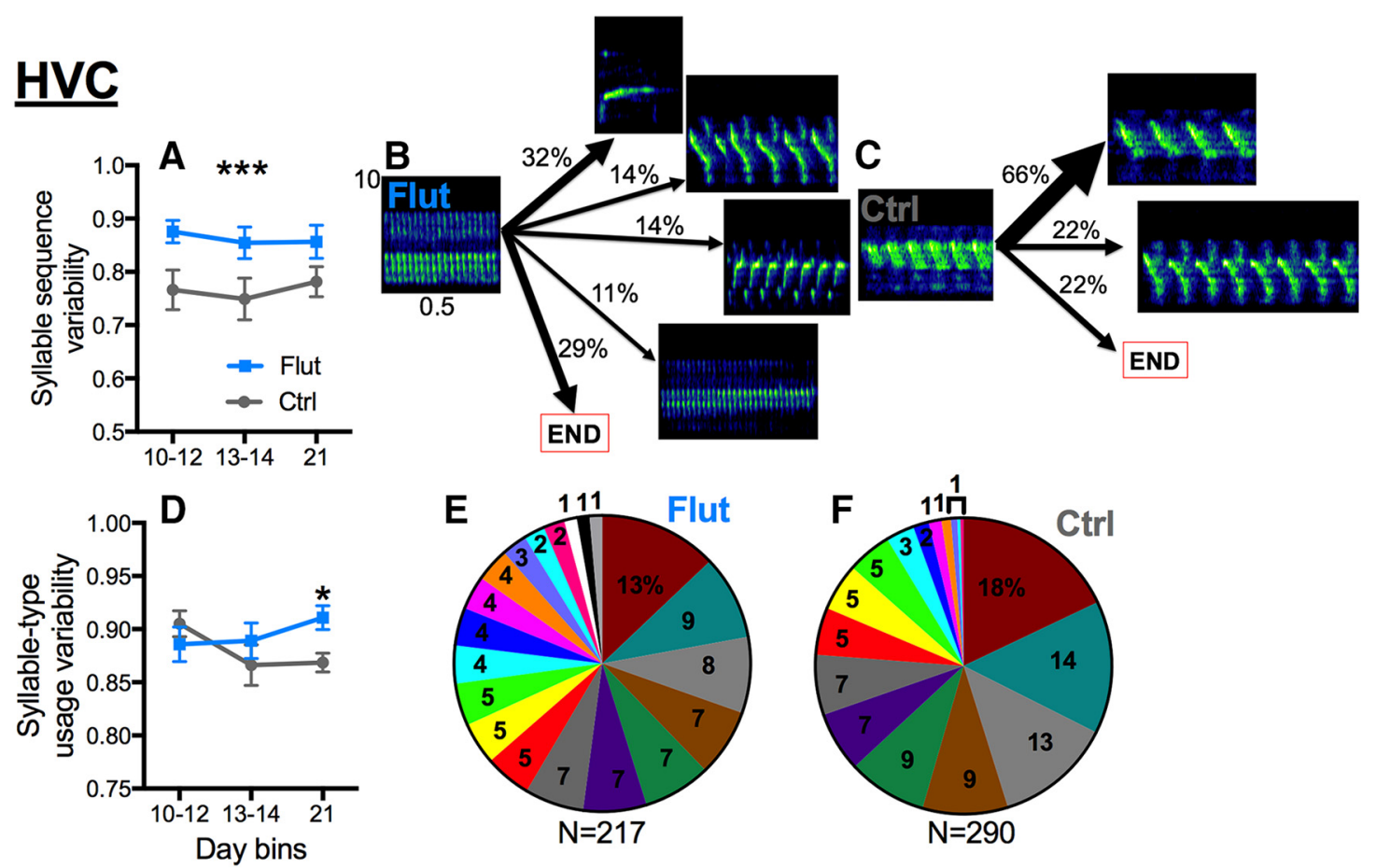

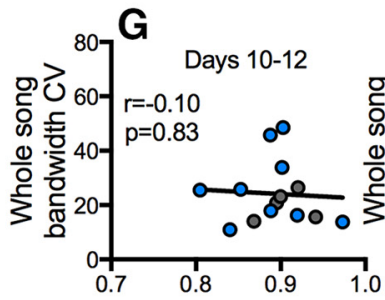

Syllable-type usage variability

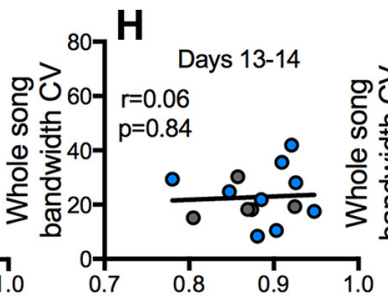

Syllable-type usage variability

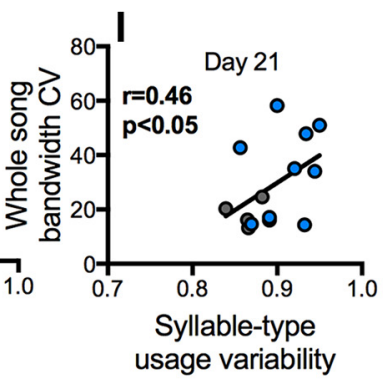

RA

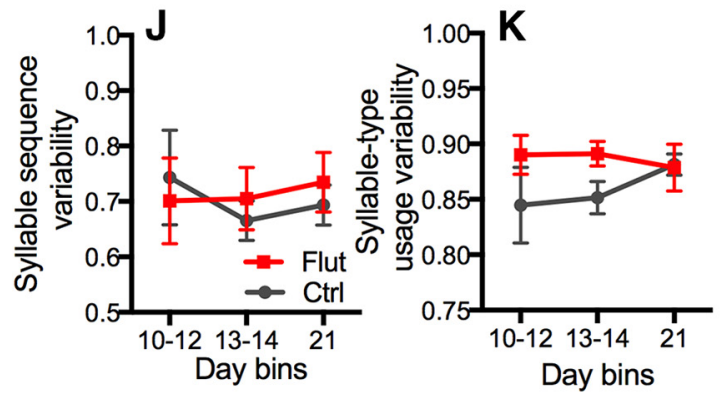

Figure 6. Androgen receptors in HVC control syllable sequence variability and syllable-type usage. A, Blocking ARs in HVC led birds to sing with enhanced syllable sequence variability (first-order entropy; see Materials and Methods). B, C, Birds treated with flutamide in HVC (Flut) showed more random (i.e., variable) transitions from their dominant syllable type compared with controls (Ctrl). $\boldsymbol{D}$, By day 21, antagonism of AR in HVC also caused birds to sing with high syllable-type usage variability (zero-order entropy; see Materials and Methods). $\boldsymbol{E}, \boldsymbol{F}$, Pie charts showing the proportion of use of different syllables (each slice = different syllable). Use of different syllables was more equally distributed (i.e., closer to a random distribution) in flutamide birds compared with control birds. G-I, Syllable-type usage variability correlated positively with whole-song bandwidth CV (the higher the bandwidth CV, the less stereotypic) only on day 21 (I) but not on the two previous time points $(\mathbf{G}, \boldsymbol{H})$, which is when birds with their AR in HVC blocked sang with significantly more whole-song bandwidth CV compared with controls (Fig. 2C-E). There were no differences between birds treated with flutamide-filled cannula in RA (Flut) and controls (Ctrl) in terms of syllable sequence variability $(\boldsymbol{J})$ or syllable-type usage variability $(\boldsymbol{K}$; first-order and zero-order entropy; see Materials and Methods). In $\boldsymbol{A}$ and $\boldsymbol{D}$, symbols represent mean \pm SEM. ${ }^{* * * A t}$ the top of a graph indicates $p<0.01$ for the overall effect of treatment in $\boldsymbol{A} ;{ }^{*} p<0.05$ comparing Flut to Ctrl on day 21 in $\boldsymbol{B}$. $\boldsymbol{G}-\mathbf{I}$, Symbols for individual birds are color-coded as in $\boldsymbol{A}, \boldsymbol{B}$.

$p=0.73$ ) or syllable-type usage variability (Fig. $6 K$; time, $p=$ 0.74 ; treatment, $p=0.09$; time $\times$ treatment, $p=0.43$ ).

Temporal properties of song are differentially regulated by androgen signaling in $\mathrm{HVC}$ and RA

Aspects of song timing, such as the duration of different units of song, may also be differentially controlled by HVC versus RA
(Arnold, 1975; Long and Fee, 2008). HVC-flut birds did not differ from control birds in terms of whole-song duration (Fig. 7A; time, $p=0.14$; treatment, $p=0.08$; time $\times$ treatment, $p=0.36$ ); however, HVC-flut birds sang longer trills compared with controls (Fig. $7 B$; time, $p=0.65$; treatment, $p=0.04, \eta_{\mathrm{p}}^{2}=0.30$; time $\times$ treatment, $p=0.38$ ). Antagonism of AR in RA caused these birds to sing longer whole songs than controls (Fig. 7C; 


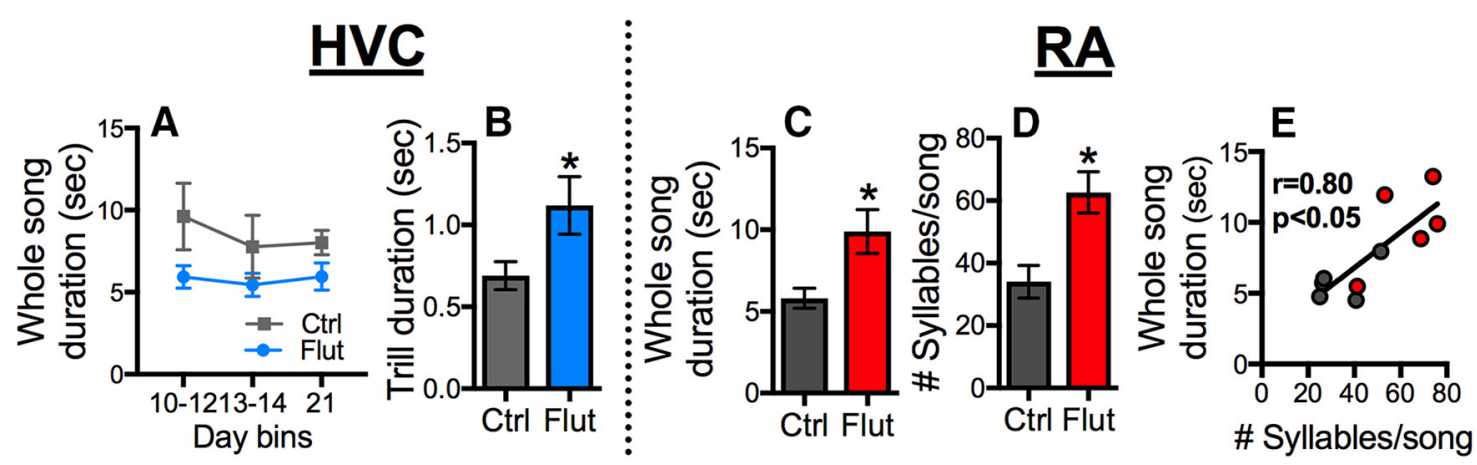

Figure 7. Blocking androgen receptors in HVC causes birds to sing trills of longer duration, whereas blockade of androgen receptors in RA extends song duration by causing birds to sing more syllables per song. $\boldsymbol{A}$, Androgen signaling in HVC does not appear to control whole-song duration; ( $\boldsymbol{B}$ ) however, blockade of androgen signaling in HVC with flutamide (Flut) leads birds to produce trills of longer duration compared with controls (Ctrl). C, Birds with their androgen receptors in RA blocked (Flut) sang longer songs than controls (Ctrl), ( $\boldsymbol{D}, \boldsymbol{E})$ an effect driven by these birds singing more syllables per song. Bars represent mean \pm SEM. ${ }^{*} p<0.05$ for an effect of treatment. Symbols in $\boldsymbol{C}$ for individual birds are color-coded like as $\boldsymbol{A}, \boldsymbol{B}$.

time, $p=0.43$; treatment, $p=0.02, \eta_{\mathrm{p}}^{2}=0.50$; time $\times$ treatment, $p=0.20)$. This effect was driven by an overall increase in the number of individual syllables per whole song (Fig. 7D; time, $p=$ 0.68 ; treatment, $p=0.01, \eta_{\mathrm{p}}^{2}=0.59$; time $\times$ treatment, $\left.p=0.77\right)$. At the individual level, whole-song duration and number of syllables per song were positively correlated in birds treated with flutamide in RA and their controls (Fig. 7E; $r=0.80, p=0.005$ ).

\section{Discussion}

By selectively blocking androgen action in HVC and RA we have provided insight into how the steroid hormone $\mathrm{T}$ regulates specific features of learned birdsong in a localized manner. It is often assumed that $\mathrm{T}$ modulates behavior in rather general ways, such as changing the probability and intensity of a behavioral response to a given stimulus. HVC and RA are clear candidates for a marked regulation by $\mathrm{T}$ based on the enriched localization of $\mathrm{AR}$ protein (Balthazart et al., 1992) or mRNA (Gahr and Metzdorf, 1997; Bernard et al., 1999) within these nuclei. However, HVC and RA are not involved in the motivation to sing as was clear from the initial lesions studies of song nuclei (Nottebohm et al., 1976), where lesions to HVC blocked song production but not movements associated with trying to sing. The current study indicates that androgens act on specific aspects of song related broadly to stereotypy and temporal features of song organization. In particular, androgen signaling in RA regulates the bandwidth stereotypy of syllables and trills (Fig. $5 C-M$ ), whereas androgen signaling in HVC regulates the variability of syllable sequencing and syllable-type usage (Fig. 6A-I). Androgen signaling in both $\mathrm{HVC}$ and RA regulates the duration of different components of song (Fig. 7): androgens in HVC regulate trill duration while androgens in RA reduce whole-song length by regulating the number of notes per whole songs. Flutamide may have preferentially affected the lateral HVC; however, because syllable sequencing was affected by flutamide implanted lateral to HVC and this song feature is thought to be regulated by medial HVC (Basista et al., 2014), this suggests that medial HVC was also exposed to flutamide, albeit possibly at a lower concentration. Nonetheless, effects obtained by exposing HVC and RA to the same compound were very different, which indicates anatomical specificity in androgen action on these two nuclei. In this discussion, we will try to link concisely known cellular and neurophysiological effects of T in HVC and RA to our behavioral effects of AR blockade.
Possible neuronal and molecular mechanisms underlying the androgenic regulation of song stereotypy: linking cellular actions of $\mathrm{T}$ with behavioral outcomes

AR are expressed in both HVC and RA and AR-positive neurons in HVC project to either RA or Area X (Sohrabji et al., 1989; for review, see Bottjer and Johnson, 1997). Androgen signaling has been implicated in regulating several neural features in HVC and RA (for review, see Brenowitz, 2015; Brenowitz and Larson, 2015), including overall changes in nuclei volumes, neuronal soma size and neuron density, and in HVC the incorporation of new neurons that mostly project to RA. All these changes in HVC are enhanced by $\mathrm{T}$ action via its androgenic and estrogenic metabolites (Smith et al., 1995, 1997a,b; Tramontin et al., 2000; Brenowitz and Lent, 2002; Sartor et al., 2005; Meitzen et al., 2007; Yamamura et al., 2011; Alward et al., 2016c). The addition of new neurons in HVC of adult zebra finches is positively associated with song stereotypy (Pytte et al., 2012). Thus, effects of AR antagonism in HVC on syllable sequence variability, syllable-type usage variability, and temporal features of song (i.e., trill duration) might be due to a reduction in the addition of new neurons in HVC, which would explain the rather long latency between beginning of treatment and some of the observed effects. HVC neurons fire sparsely, in a chain-like manner during song and this activity is thought to underlie song timing (Hahnloser et al., 2002; Long and Fee, 2008). HVC neurons also show coding properties that relate to the ordering of song syllables (Bouchard and Brainard, 2013) that were likely also altered by the blockade of AR in HVC.

It took $21 \mathrm{~d}$ to reduce whole-song bandwidth stereotypy and enhance syllable-type usage variability in HVC-flut birds compared with HVC-ctrl birds. Similarly, in male white-crowned sparrows T-treated males increased song stereotypy by day 21 compared with day 13, but treatment with AR and ER antagonists in HVC prevented this increase from occurring (Meitzen et al., 2007). The enhancement in syllable sequence variability caused by the blockade of androgen signaling in HVC occurred much sooner. These differences may reflect HVC's topographical specializations in terms of function and hodology (Basista et al., 2014). The topographical specificity of HVC's afferents or function may cause dissociation in the manner in which certain song features are regulated by androgen signaling within HVC.

This dissociation might alternatively originate in specific effects of $\mathrm{AR}$ antagonism in $\mathrm{HVC}$ on RA function. In whitecrowned sparrows treatment of HVC with AR or ER antagonists 


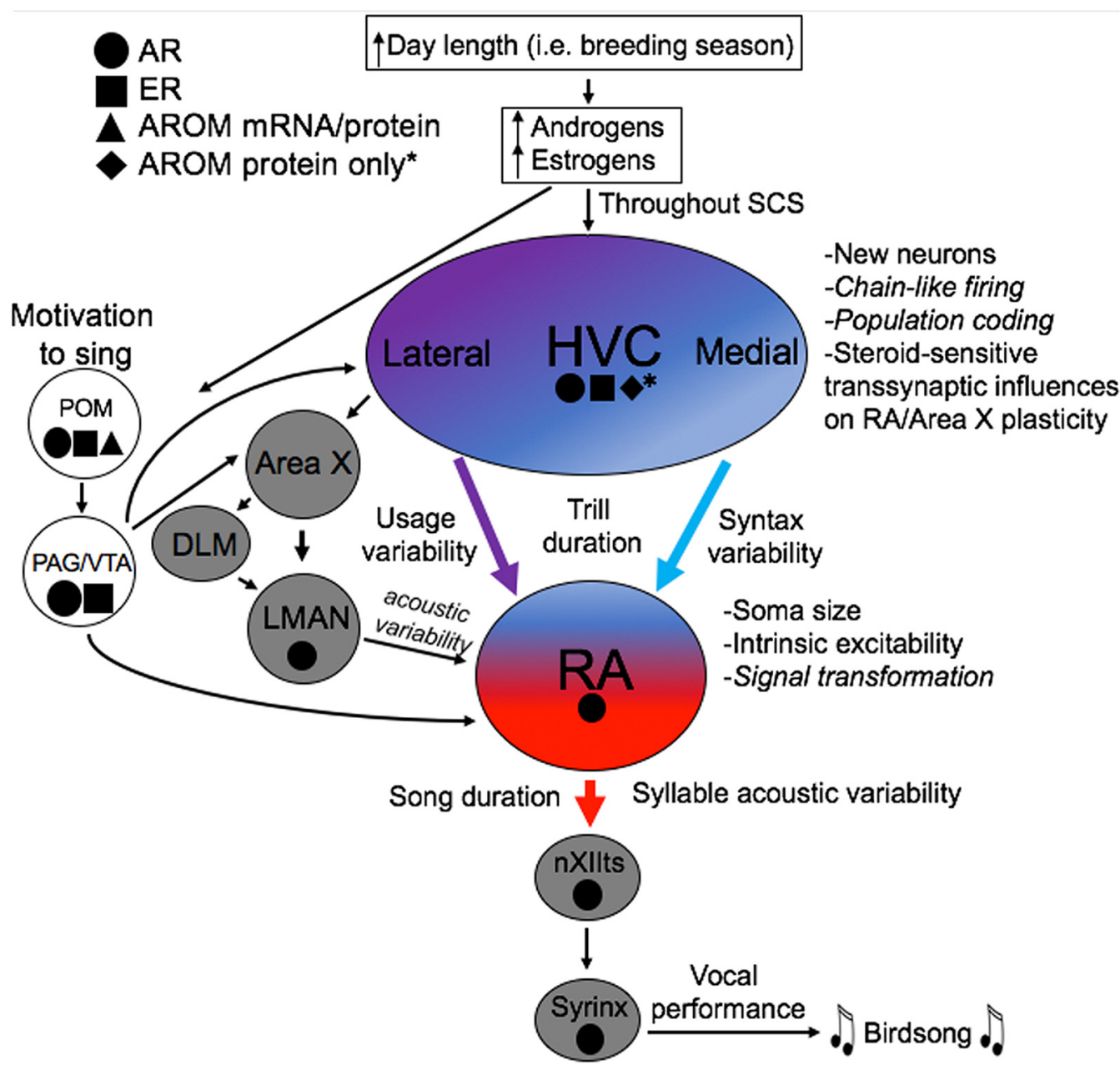

Figure 8. Working model of the regulation of birdsong by androgen signaling. This model posits that increased androgens and estrogens (e.g., during the breeding season) act at multiple sites in the songbird brain to regulate distinct features of birdsong by modulating neurophysiological features. Androgens act in an anatomically distinct nonredundant manner to regulate specific features of birdsong, but these effects are also modulated by the transsynaptic feedback between these nuclei. Previous studies indicate androgens and estrogens acting within the POM may regulate the motivation to sing (Alward et al., 2013, 2016c). The POM likely influences the song control system indirectly, via projections to the ventral tegmental area (VTA) and/or periaqueductal gray (PAG; Riters and Alger, 2004), which project to HVC (proper name), RA, and Area X (Appeltants et al., 2000, 2002; (astelino et al., 2007). There is also evidence that estrogens acting within HVC regulate song stereotypy (Meitzen et al., 2007). Aromatase (AROM) expression has been found within the POM in multiple songbirds, including canaries (Shen et al., 1995; Fusani et al., 2000), whereas AROM protein (in the absence of detectable AROM mRNA) has been found within presynaptic boutons within HVC in zebra finches (Peterson et al., 2005). Therefore, in addition to the potential actions of estrogens of a gonadal origin acting in the POM and HVC to regulate song, actions of estrogens generated from testosterone within these nuclei is also possible. There is also evidence that neural activity/hormone action in one region can influence morphological or neurophysiology characteristics in downstream or upstream brain regions (Brenowitz and Lent, 2002; Meitzen et al., 2007; Larson et al., 2013; Brenowitz, 2015; Alward et al., 2016c), which could affect control of song. All song features listed in italics are predicted to be controlled by androgens and/or estrogens based on the results of past studies (Spiro et al., 1999; Long and Fee, 2008; Picardo et al., 2016). HVC is colored as a gradient to represent the topographical nature of its functions: lateral HVC controls aspects of syllable usage, whereas medial HVC controls aspects of syntax (Basista et al., 2014). RA is also colored as gradient to represent the fact that it receives input from both HVC and LMAN, but then transforms these signals into firing patterns whose variability correlates to the variability of individual acoustic units of song (e.g., syllables; Spiro et al., 1999). LMAN is part of a circuit including Area X and the dorsolateral nucleus of the medial anterior thalamus (DLM) that is critical for song learning. RA projects to the tracheosyringeal portion of the twelfth cranial nerve (nXIIts), a hindbrain nucleus that contains androgen-sensitive motor neurons (Harding, 2008). nXIlts neurons control muscles of the syrinx, which are also androgen sensitive, to generate song. We have shown previously that androgens at the syrinx regulate aspects of vocal performance without affecting the motivation to sing or song stereotypy (Alward et al., 2016b). The basic principle of steroid hormone action in the regulation of a complex behavior presented here, that steroid hormones act in a nonredundant manner throughout the brain and periphery to regulate behavior, may be applicable to a wide-range of behaviors and systems. SCS, Song control system.

leads to a decrease in soma area and spontaneous firing rate within RA by day 21 (Meitzen et al., 2007). Moreover, systemic T and exposure to LD photoperiod caused an increase in spontaneous firing rate at day 21 compared with day 0 . However, days 4 , 11 , and 14 were not different from day 0 . A similar pattern was observed for RA neuron size. Importantly, RA neurons transform HVC input that is relayed to the hindbrain and then to the syrinx to produce song (Spiro et al., 1999). It can thus be hypothesized that blockade of AR signaling in HVC leads to a perturbation in RA's ability to transform HVC input on day 21 , specifically as it relates to syllable usage variability, thus leading to the observed effects.
Multiple studies have also shown that firing patterns in RA neurons strongly correlate with the acoustic structure of individual syllables (Yu and Margoliash, 1996; Margoliash, 1997; Sober et al., 2008). Because blockade of AR in RA reduces spontaneous firing rate and soma size (Meitzen et al., 2007), it can be assumed that this perturbation in neural firing contributes to the decreased bandwidth stereotypy in syllables, trills, and overall song observed here.

Alternatively, the speed of NMDA-EPSPs in RA inversely correlates with the potential for vocal plasticity (Livingston et al., 2000). Androgens can speed up NMDA-EPSPs leading to prema- 
turely crystallized song in juvenile songbirds (White et al., 1999; Livingston and Mooney, 2001), suggesting that androgens attenuate vocal plasticity circuitry. Therefore, AR antagonism in RA might have decreased the speed of NMDA-EPSPs, thus increasing vocal variability as observed here (Livingston et al., 2000; Livingston and Mooney, 2001).

The lateral magnocellular nucleus of the anterior nidopallium (LMAN) is also known to regulate acoustic but not syntactical stereotypy (for review, see Brainard and Doupe, 2013). LMAN is thought to introduce acoustic variability into song via RA. We found here that antagonism of androgen receptors in RA reduced bandwidth stereotypy of individual song units (i.e., syllables) without affecting syntactical features. This suggests that AR antagonism in RA potentially perturbed LMAN-RA synapses or significantly influenced RA's ability to transform LMAN input (Spiro et al., 1999). However, according to this hypothesis, blocking AR in RA should have affected features regulated by HVC as well, unless there is segregation of afferent input in androgensensitive RA neurons. Data from Stark and Perkel (1999) support this contention. HVC input to RA is mediated by NMDA and AMPA receptors whereas LMAN input to RA is mediated almost exclusively by NMDA receptors. HVC-RA and LMAN-RA synapses are thus partially segregated based on the different complements of glutamate receptors. The partial segregation of HVC-RA and LMAN-RA synapses may help to explain some of the current findings.

We also observed that AR antagonism in HVC enhanced syllable-type usage variability and on days 13-14 AR antagonism in RA led to a nonsignificant increase in syllable-type usage variability, but this difference disappeared by day 21 . These results suggest that variation in syllable-type usage is encoded in HVC, but retrograde feedback from RA can affect this process due to its regulation of the addition of new neurons into HVC (Larson et al., 2013).

Role for estrogenic signaling in the regulation of song stereotypy Although this study did not investigate the role of estrogen signaling, we can make predictions about its role in regulating some of the song features affected here. Meitzen et al. (2007) have shown that blockade of both ARs and ERs in HVC of whitecrowned sparrows reduces song stereotypy and also spontaneous firing rate in RA. Moreover, acute inhibition of aromatase, the enzyme that converts $\mathrm{T}$ to estradiol, can rapidly and reversibly reduce overall song bandwidth stereotypy in canaries (Alward et al., 2016a). ER is only expressed in HVC, so it is possible that estrogen signaling in HVC regulates aspects of syllable-type usage variability, syntax, and temporal aspects of trills.

\section{Conclusion: working model on the regulation of birdsong by steroid hormones}

It is an old idea that steroids can modulate physiological state to change the probability of producing a particular behavior, and this applies to birdsong in that $\mathrm{T}$ action in the hypothalamus regulates the motivation to sing (Alward et al., 2013). However, in this study we showed by blocking androgen signaling in two cortical-like brain regions that $\mathrm{T}$ regulates complex features of song performance such as syllable bandwidth stereotypy, syllable sequencing, syllable-type usage, and the temporal organization of song in a nonredundant fashion. These findings indicate that steroids regulate behavior in a more precise manner than previously thought. Wilson $(1975$, p. 6) opined that hormones would prove to be less important for our understanding of the neural control of behavior because they represented "crude tuning devices" that lacked explanatory power. The present demonstration of specific actions of androgens on cognitive aspects of birdsong controlled by cortical-like brain regions shows the limitation of such claims. Combining the current results with past observations and other models (Ball et al., 2002; Meitzen et al., 2007; Meitzen and Thompson, 2008; Balthazart and Ball, 2016; Alward et al., 2017), we propose a working model illustrating how steroid hormones may regulate birdsong at multiple levels (Fig. 8). This model includes the highly localized, nonredundant effects of sex steroid hormones in the regulation of brain and behavior, but also considers the interactions between individual hormonesensitive nuclei of the song control system.

\section{References}

Alward BA, Balthazart J, Ball GF (2013) Differential effects of global versus local testosterone on singing behavior and its underlying neural substrate. Proc Natl Acad Sci U S A 110:19573-19578. CrossRef Medline

Alward BA, Mayes WD, Peng K, Stevenson TJ, Balthazart J, Ball GF (2014) Dissociable effects of social context on song and doublecortin immunoreactivity in male canaries. Eur J Neurosci 40:2941-2947. CrossRef Medline

Alward BA, de Bournonville C, Chan TT, Balthazart J, Cornil CA, Ball GF (2016a) Aromatase inhibition rapidly affects in a reversible manner distinct features of birdsong. Sci Rep 6:32344. CrossRef Medline

Alward BA, Madison FN, Gravley WT, Ball GF (2016b) Antagonism of syringeal androgen receptors reduces the quality of female-preferred male song in canaries. Anim Behav 119:201-212. CrossRef

Alward BA, Madison FN, Parker SE, Balthazart J, Ball GF (2016c) Pleiotropic control by testosterone of a learned vocal behavior and its underlying neuroplasticity. eNeuro 3:ENEURO.0145-15.2016. CrossRef Medline

Alward BA, Rouse ML, Balthazart J, Ball GF (2017) Testosterone regulates birdsong in an anatomically specific manner. Anim Behav 124:291-298. CrossRef

Appeltants D, Absil P, Balthazart J, Ball GF (2000) Identification of the origin of catecholaminergic inputs to HVc in canaries by retrograde tract tracing combined with tyrosine hydroxylase immunocytochemistry. J Chem Neuroanat 18:117-133. CrossRef Medline

Appeltants D, Ball GF, Balthazart J (2002) The origin of catecholaminergic inputs to the song control nucleus RA in canaries. Neuroreport 13:649653. CrossRef Medline

Arnold AP (1975) The effects of castration and androgen replacement on song, courtship, and aggression in zebra finches (Poephila guttata). J Exp Zool 191:309-326. CrossRef Medline

Ball GF, Riters LV, Balthazart J (2002) Neuroendocrinology of song behavior and avian brain plasticity: multiple sites of action of sex steroid hormones. Front Neuroendocrinol 23:137-178. CrossRef Medline

Balthazart J, Ball GF (2016) Endocrine and social regulation of adult neurogenesis in songbirds. Front Neuroendocrinol 41:3-22. CrossRef Medline

Balthazart J, Surlemont C (1990) Androgen and estrogen action in the preoptic area and activation of copulatory behavior in quail. Physiol Behav 48:599-609. CrossRef Medline

Balthazart J, Foidart A, Wilson EM, Ball GF (1992) Immunocytochemical localization of androgen receptors in the male songbird and quail brain. J Comp Neurol 317:407-420. CrossRef Medline

Basista MJ, Elliott KC, Wu W, Hyson RL, Bertram R, Johnson F (2014) Independent premotor encoding of the sequence and structure of birdsong in avian cortex. J Neurosci 34:16821-16834. CrossRef Medline

Bernard DJ, Bentley GE, Balthazart J, Turek FW, Ball GF (1999) Androgen receptor, estrogen receptor alpha, and estrogen receptor beta show distinct patterns of expression in forebrain song control nuclei of European starlings. Endocrinology 140:4633-4643. CrossRef Medline

Bottjer SW, Hewer SJ (1992) Castration and antisteroid treatment impair vocal learning in male zebra finches. J Neurobiol 23:337-353. CrossRef Medline

Bottjer SW, Johnson F (1997) Circuits, hormones, and learning: vocal behavior in songbirds. J Neurobiol 33:602-618. CrossRef Medline

Bouchard KE, Brainard MS (2013) Neural encoding and integration of learned probabilistic sequences in avian sensory-motor circuitry. J Neurosci 33:17710-17723. CrossRef Medline

Brainard MS, Doupe AJ (2013) Translating birdsong: songbirds as a model for basic and applied medical research. Annu Rev Neurosci 36:489-517. CrossRef Medline 
Brenowitz EA, Perkel DJ, Osterhout L (2010) Language and birdsong: introduction to the special issue. Brain Lang 115:1-2. CrossRef Medline

Brenowitz EA (2015) Transsynaptic trophic effects of steroid hormones in an avian model of adult brain plasticity. Front Neuroendocrinol 37:119128. CrossRef Medline

Brenowitz EA, Larson TA (2015) Neurogenesis in the adult avian song control system. Cold Spring Harb Perspect Biol 7:a019000. CrossRef Medline

Brenowitz EA, Lent K (2002) Act locally and think globally: intracerebral testosterone implants induce seasonal-like growth of adult avian song control circuits. Proc Natl Acad Sci U S A 99:12421-12426. CrossRef Medline

Brown TR (2004) Nonsteroidal selective androgen receptors modulators (SARMs): designer androgens with flexible structures provide clinical promise. Endocrinology 145:5417-5419. CrossRef Medline

Calder WA (1970) Respiration during song in the canary (Serinus canaria). Comp Biochem Physiol 32:251-258. CrossRef Medline

Castelino CB, Diekamp B, Ball GF (2007) Noradrenergic projections to the song control nucleus area $\mathrm{x}$ of the medial striatum in male zebra finches (Taeniopygia guttata). J Comp Neurol 502:544-562. CrossRef Medline

Catchpole CK, Slater PJ (2003) Bird song: biological themes and variations. Cambridge, UK: Cambridge UP.

Doupe AJ, Kuhl PK (1999) Birdsong and human speech: common themes and mechanisms. Annu Rev Neurosci 22:567-631. CrossRef Medline

Fusani L, Van't Hof T, Hutchison JB, Gahr M (2000) Seasonal expression of androgen receptors, estrogen receptors, and aromatase in the canary brain in relation to circulating androgens and estrogens. J Neurobiol 43:254-268. CrossRef Medline

Fuxjager MJ, Barske J, Du S, Day LB, Schlinger BA (2012) Androgens regulate gene expression in avian skeletal muscles. PLoS One 7:e51482. CrossRef Medline

Gahr M (2001) Distribution of sex steroid hormone receptors in the avian brain: functional implications for neural sex differences and sexual behaviors. Microsc Res Tech 55:1-11. CrossRef Medline

Gahr M, Metzdorf R (1997) Distribution and dynamics in the expression of androgen and estrogen receptors in vocal control systems of songbirds. Brain Res Bull 44:509-517. CrossRef Medline

Gahr M, Voigt C, Leitner S (2001) Seasonal changes in the song pattern of the non-domesticated island canary (Serinus canaria): a field study. Behaviour 138:885-904. CrossRef

Grisham W, Park SH, Hsia JK, Kim C, Leung MC, Kim L, Arnold AP (2007) Effects of long-term flutamide treatment during development in zebra finches. Neurosci Lett 418:92-96. CrossRef Medline

Hahnloser RH, Kozhevnikov AA, Fee MS (2002) An ultra-sparse code underlies the generation of neural sequences in a songbird. Nature 419:6570. CrossRef Medline

Hampton CM, Sakata JT, Brainard MS (2009) An avian basal gangliaforebrain circuit contributes differentially to syllable versus sequence variability of adult Bengalese finch song. J Neurophysiol 101:3235-3245. CrossRef Medline

Harding CF (2008) Hormonal modulation of singing behavior: methodology and principles of hormone action. In: Neuroscience of birdsong (Zeigler PH, Marler P, eds), pp 305-319. Cambridge, UK: Cambridge UP

Hejmej A, Górowska E, Kotula-Balak M, Chojnacka K, Zarzycka M, Zając J, Bilinska B (2013) Androgen signaling disruption during fetal and postnatal development affects androgen receptor and connexin 43 expression and distribution in adult boar prostate. Biomed Res Int 2013:407678. CrossRef Medline

Hultsch H, Todt D (2004) Learning to sing. In: Nature's music: the science of birdsong (Marler PR, Slabbekoorn H, eds), pp 80-106. San Diego: Elsevier Academic.

Hurley LL, Wallace AM, Sartor JJ, Ball GF (2008) Photoperiodic induced changes in reproductive state of border canaries (Serinus canaria) are associated with marked variation in hypothalamic gonadotropin-releasing hormone immunoreactivity and the volume of song control regions. Gen Comp Endocrinol 158:10-19. CrossRef Medline

Iserbyt A, Eens M, Baetens W, Vermeulen A, Müller W (2017) Within- and between-individual (co) variance partitioning reveals limited pleiotropic effects of testosterone on immune function, sexual signaling, and parental investment. Behav Ecol Sociobiol 71:74. CrossRef

Johnson JS, Newport EL (1989) Critical period effects in second language learning: the influence of maturational state on the acquisition of English as a second language. Cogn Psychol 21:60-99. CrossRef Medline
Kung KT, Browne WV, Constantinescu M, Noorderhaven RM, Hines M (2016) Early postnatal testosterone predicts sex-related differences in early expressive vocabulary. Psychoneuroendocrinology 68:111-116. CrossRef Medline

Larson TA, Wang TW, Gale SD, Miller KE, Thatra NM, Caras ML, Perkel DJ, Brenowitz EA (2013) Postsynaptic neural activity regulates neuronal addition in the adult avian song control system. Proc Natl Acad Sci U S A 110:16640-16644. CrossRef Medline

Leitner S, Voigt C, Garcia-Segura LM, Van't Hof T, Gahr M (2001) Seasonal activation and inactivation of song motor memories in wild canaries is not reflected in neuroanatomical changes of forebrain song areas. Horm Behav 40:160-168. CrossRef Medline

Lipkind D, Marcus GF, Bemis DK, Sasahara K, Jacoby N, Takahasi M, Suzuki K, Feher O, Ravbar P, Okanoya K, Tchernichovski O (2013) Stepwise acquisition of vocal combinatorial capacity in songbirds and human infants. Nature 498:104-108. CrossRef Medline

Livingston FS, Mooney R (2001) Androgens and isolation from adult tutors differentially affect the development of songbird neurons critical to vocal plasticity. J Neurophysiol 85:34-42. Medline

Livingston FS, White SA, Mooney R (2000) Slow NMDA-EPSCs at synapses critical for song development are not required for song learning in zebra finches. Nat Neurosci 3:482-488. CrossRef Medline

Long MA, Fee MS (2008) Using temperature to analyse temporal dynamics in the songbird motor pathway. Nature 456:189-194. CrossRef Medline

Madison FN, Rouse ML Jr, Balthazart J, Ball GF (2015) Reversing song behavior phenotype: testosterone driven induction of singing and measures of song quality in adult male and female canaries (Serinus canaria). Gen Comp Endocrinol 215:61-75. CrossRef Medline

Margoliash D (1997) Distributed time-domain representations in the birdsong system. Neuron 19:963-966. CrossRef Medline

Markowitz JE, Ivie E, Kligler L, Gardner TJ (2013) Long-range order in canary song. Plos Comput Biol 9:e1003052. CrossRef Medline

Marler P (1970) Birdsong and speech development: could there be parallels? Am Sci 58:669-673. Medline

Marler P, Peters S, Ball GF, Dufty AM Jr, Wingfield JC (1988) The role of sex steroids in the acquisition and production of birdsong. Nature 336:770772. CrossRef Medline

Matheson LE, Sun H, Sakata JT (2016) Forebrain circuits underlying the social modulation of vocal communication signals. Dev Neurobiol 76:4763. CrossRef Medline

Meitzen J, Thompson CK (2008) Seasonal-like growth and regression of the avian song control system: neural and behavioral plasticity in adult male Gambel's white-crowned sparrows. Gen Comp Endocrinol 157:259-265. CrossRef Medline

Meitzen J, Moore IT, Lent K, Brenowitz EA, Perkel DJ (2007) Steroid hormones act transsynaptically within the forebrain to regulate neuronal phenotype and song stereotypy. J Neurosci 27:12045-12057. CrossRef Medline

Meitzen J, Thompson CK, Choi H, Perkel DJ, Brenowitz EA (2009) Time course of changes in Gambel's white-crowned sparrow song behavior following transitions in breeding condition. Horm Behav 55:217-227. CrossRef Medline

Naghdi N, Nafisy N, Majlessi N (2001) The effects of intrahippocampal testosterone and flutamide on spatial localization in the Morris water maze. Brain Res 897:44-51. CrossRef Medline

Nicholls TJ, Storey CR (1977) The effect of duration of the daily photoperiod on recovery of photosensitivity in photorefractory canaries (Serinus canarius). Gen Comp Endocrinol 31:72-74. CrossRef Medline

Nottebohm F, Stokes TM, Leonard CM (1976) Central control of song in the canary, Serinus canarius. J Comp Neurol 165:457-486. CrossRef Medline

Nottebohm F, Nottebohm ME, Crane L (1986) Developmental and seasonal changes in canary song and their relation to changes in the anatomy of song-control nuclei. Behav Neural Biol 46:445-471. CrossRef Medline

Parker SD (2009) Heterospecific vocal mimicry in Cassin's finch (Carpodacus cassinii): a descriptive analysis. $\mathrm{PhD}$ thesis, University of California, Davis.

Peterson RS, Yarram L, Schlinger BA, Saldanha CJ (2005) Aromatase is presynaptic and sexually dimorphic in the adult zebra finch brain. Proc Biol Sci 272:2089-2096. CrossRef Medline

Picardo MA, Merel J, Katlowitz KA, Vallentin D, Okobi DE, Benezra SE, Clary RC, Pnevmatikakis EA, Paninski L, Long MA (2016) Population-level representation of a temporal sequence underlying song production in the zebra finch. Neuron 90:866-876. CrossRef Medline 
Pytte CL, George S, Korman S, David E, Bogdan D, Kirn JR (2012) Adult neurogenesis is associated with the maintenance of a stereotyped, learned motor behavior. J Neurosci 32:7052-7057. CrossRef Medline

Riters LV, Alger SJ (2004) Neuroanatomical evidence for indirect connections between the medial preoptic nucleus and the song control system: possible neural substrates for sexually motivated song. Cell Tissue Res 316:35-44. CrossRef Medline

Sakata JT, Hampton CM, Brainard MS (2008) Social modulation of sequence and syllable variability in adult birdsong. J Neurophysiol 99: 1700-1711. CrossRef Medline

Sartor JJ, Balthazart J, Ball GF (2005) Coordinated and dissociated effects of testosterone on singing behavior and song control nuclei in canaries (Serinus canaria). Horm Behav 47:467-476. CrossRef Medline

Shen P, Schlinger BA, Campagnoni AT, Arnold AP (1995) An atlas of aromatase mRNA expression in the zebra finch brain. J Comp Neurol 360: 172-184. CrossRef Medline

Singh SM, Gauthier S, Labrie F (2000) Androgen receptor antagonists (antiandrogens): structure-activity relationships. Curr Med Chem 7:211247. CrossRef Medline

Smith GT, Brenowitz EA, Wingfield JC, Baptista LF (1995) Seasonal changes in song nuclei and song behavior in Gambel's white-crowned sparrows. J Neurobiol 28:114-125. CrossRef Medline

Smith GT, Brenowitz EA, Prins GS (1996) Use of PG-21 immunocytochemistry to detect androgen receptors in the songbird brain. J Histochem Cytochem 44:1075-1080. CrossRef Medline

Smith GT, Brenowitz EA, Beecher MD, Wingfield JC (1997a) Seasonal changes in testosterone, neural attributes of song control nuclei, and song structure in wild songbirds. J Neurosci 17:6001-6010. Medline

Smith GT, Brenowitz EA, Wingfield JC (1997b) Roles of photoperiod and testosterone in seasonal plasticity of the avian song control system. J Neurobiol 32:426-442. CrossRef Medline

Sober SJ, Wohlgemuth MJ, Brainard MS (2008) Central contributions to acoustic variation in birdsong. J Neurosci 28:10370-10379. CrossRef Medline

Sohrabji F, Nordeen KW, Nordeen EJ (1989) Projections of androgenaccumulating neurons in a nucleus controlling avian song. Brain Res 488:253-259. CrossRef Medline

Soma KK, Hartman VN, Wingfield JC, Brenowitz EA (1999a) Seasonal changes in androgen receptor immunoreactivity in the song nucleus $\mathrm{HVc}$ of a wild bird. J Comp Neurol 409:224-236. CrossRef Medline

Soma KK, Sullivan K, Wingfield J (1999b) Combined aromatase inhibitor and antiandrogen treatment decreases territorial aggression in a wild songbird during the nonbreeding season. Gen Comp Endocrinol 115: 442-453. CrossRef Medline

Spiro JE, Dalva MB, Mooney R (1999) Long-range inhibition within the zebra finch song nucleus RA can coordinate the firing of multiple projection neurons. J Neurophysiol 81:3007-3020. Medline

Stark LL, Perkel DJ (1999) Two-stage, input-specific synaptic maturation in a nucleus essential for vocal production in the zebra finch. J Neurosci 19:9107-9116. Medline

Stauffer TR, Elliott KC, Ross MT, Basista MJ, Hyson RL, Johnson F (2012) Axial organization of a brain region that sequences a learned pattern of behavior. J Neurosci 32:9312-9322. CrossRef Medline

Tchernichovski O, Mitra PP, Lints T, Nottebohm F (2001) Dynamics of the vocal imitation process: how a zebra finch learns its song. Science 291: 2564-2569. CrossRef Medline

Tchernichovski O, Marcus G (2014) Vocal learning beyond imitation: mechanisms of adaptive vocal development in songbirds and human infants. Curr Opin Neurobiol 28:42-47. CrossRef Medline

Tramontin AD, Hartman VN, Brenowitz EA (2000) Breeding conditions induce rapid and sequential growth in adult avian song control circuits: a model of seasonal plasticity in the brain. J Neurosci 20:854-861. Medline

Tramontin AD, Wingfield JC, Brenowitz EA (2003) Androgens and estrogens induce seasonal-like growth of song nuclei in the adult songbird brain. J Neurobiol 57:130-140. CrossRef Medline

Van Duyse E, Pinxten R, Snoeijs T, Eens M (2005) Simultaneous treatment with an aromatase inhibitor and an anti-androgen decreases the likelihood of dawn song in free-living male great tits, Parus major. Horm Behav 48:243-251. CrossRef Medline

Voigt C, Leitner S (2008) Seasonality in song behaviour revisited: seasonal and annual variants and invariants in the song of the domesticated canary (Serinus canaria). Horm Behav 54:373-378. CrossRef Medline

White SA, Livingston FS, Mooney R (1999) Androgens modulate NMDA receptor-mediated EPSCs in the zebra finch song system. J Neurophysiol 82:2221-2234. Medline

Wilson E (1975) Sociobiology: the new synthesis. Cambridge, MA: Harvard UP.

Yamamura T, Barker JM, Balthazart J, Ball GF (2011) Androgens and estrogens synergistically regulate the expression of doublecortin and enhance neuronal recruitment in the song system of adult female canaries. J Neurosci 31:9649-9657. CrossRef Medline

Yu AC, Margoliash D (1996) Temporal hierarchical control of singing in birds. Science 273:1871-1875. CrossRef Medline 